\title{
La cuestión ambiental en geografía histórica e historia ambiental: tradición, renovación y diálogos ${ }^{1}$
}

\author{
Hortensia Castro ${ }^{2}$
}

\begin{abstract}
RESUMEN
La indagación histórica sobre cuestiones ambientales tiene una larga tradición en Geografía, revitalizada recientemente a raíz de los debates por el deterioro de ambientes y recursos y la potenciación de riesgos. A ella se suma en las últimas décadas la Historia Ambiental, un campo afín en cuanto a preocupaciones y planteos. Bajo ese marco este artículo se interroga acerca de los principales aportes realizados sobre temas ambientales en clave histórica desde ambas áreas de estudio, más precisamente en cuanto a temas, perspectivas teórico-conceptuales y estrategias metodológicas (en el caso de la Geografía Histórica, tanto en la tradición más temprana como en las revisiones y renovaciones desarrolladas desde la década de 1980). La exploración desarrollada se concentra en una serie de autores y obras emblemáticas de la producción académica realizada al respecto en los Estados Unidos, Europa occidental y América Latina.
\end{abstract}

Palabras clave: Cuestión ambiental, Geografía Histórica, Historia Ambiental, renovación teórico-metodológica.

\begin{abstract}
Historical research on environmental issues has a long tradition within Geography. This tradition has been recently revitalized through debates on environment deterioration, natural resources and potentiation of risks. In recent decades these debates were accompanied by developments within Environmental History, a related field in terms of concerns and approaches. Within this framework, this article examines the main contributions on key environmental issues in historical perspective, more precisely, in terms of topics, theoretical and conceptual perspectives and methodological strategies made by both areas (in the case of Historical Geography, in its earlier tradition and in its renovations carried out since the early '80s). The examination focuses on a number of authors and emblematic academic texts produced in United States, Western Europe and Latin America
\end{abstract}

Key words: Environmental question, Historical Geography, Environmental History, theoretical and methodological renewal.

1 Artículo recibido el 1 de febrero de 2012, aceptado el 22 de mayo de 2012 y corregido el 18 de agosto de 2012.
2 Departamento e Instituto de Geografía, Facultad de Filosofía y Letras, Universidad de Buenos Aires (Argentina). E-mail: sitacastro@yahoo.com.ar 
Sin duda, la cuestión ambiental presenta en las últimas décadas una notable emergen$\mathrm{cia}^{3}$. En parte esa relevancia se vincula con el alto grado de transformación de las bases naturales del planeta y, a raíz de ello, las invocaciones y alertas respecto de la disipación o el "fin de la naturaleza" (McKibben, 1990); también, con el deterioro progresivo y acelerado de ambientes y recursos naturales y la consecuente generación de nuevos y mayores riesgos ambientales (Coates, 1998; Boada y Saurí, 2002). Asimismo ha colaborado con esa relevancia la formación de diferentes movimientos ambientalistas y organismos especializados, así como la misma socialización de los estudios sobre aquellas transformaciones y riesgos, todo lo cual ha llevado a una explosión de esa temática en la agenda política (Nogué y Rufí, 2001; Estenssoro Saavedra, 2007).

Bajo ese marco ha venido cobrando preeminencia la necesidad de una mirada o perspectiva histórica sobre los problemas ambientales, en tanto permitiría conocer y comprender el sentido, alcance y magnitud de las transformaciones, así como sus actores y procesos centrales; asimismo, porque contribuiría a identificar y comprender las variaciones en las ideas y representaciones acerca de la naturaleza y el ambiente, así como las acciones promovidas o justificadas a través de ellas. En esto ha sido clave el impulso dado por los estudios sobre cambio climático, en tanto han expuesto la necesidad de desarrollar indagaciones bajo rangos temporales amplios (desde decenas de décadas hasta varios siglos) para definir, con mayor precisión, la presencia de continuidades, alteraciones y cambios (Boada y Saurí, 2002). Ese interés por el desarrollo de una perspectiva histórica también se produce de cara a "la veneración por los tiempos pasados", expresada parti-

\footnotetext{
3 Se entiende por ambiente al medio o entorno material, cualquiera sea su tipo y más allá de su grado natural/ social. Desde mediados del siglo XX y de la mano del ambientalismo, las referencias al término se focalizan, en particular, en el funcionamiento e interrelación de sus componentes, con énfasis en los elementos y fuerzas naturales afectadas (Lowenthal, 2000; Baker, 2003; Castro, 2011). Aquí se utiliza la expresión "cuestión ambiental" para aludir al conjunto de debates y problemáticas referido a las condiciones de ese medio o entorno.
}

cularmente en la creciente activación patrimonial de lugares, paisajes y especies, en el marco de la intensificación de las transformaciones ambientales (Sunyer, 2010: 146).

Frente a estas preocupaciones y demandas, este artículo busca examinar los aportes realizados sobre la problemática ambiental desde la Geografía Histórica; más precisamente, interesa abordar los siguientes interrogantes: ¿cuál ha sido el aporte de la Geografía Histórica sobre la cuestión ambiental?, ¿qué continuidades y discontinuidades se observan en su tradición? También se busca indagar sobre las similitudes y diferencias entre esos aportes y los de otro campo afín, la Historia Ambiental; particularmente interesa identificar qué es la Historia Ambiental y qué planteos y propuestas la caracterizan. Finalmente, qué tipo de aportes han realizado sobre la cuestión una y otra área de estudios ${ }^{4}$ y qué aspectos están en debate.

La exploración propuesta se concentra en la identificación de los planteos centrales y la presentación de algunos autores y obras emblemáticas, tanto de la producción académica realizada en los Estados Unidos y Europa occidental como en América Latina. No se pretende realizar un recorrido exhaustivo ni, menos aún, definitivo; la finalidad general es poner en diálogo los aportes realizados acerca de los problemas ambientales en clave histórica desde ambas áreas.

Para desarrollar aquellos objetivos, este artículo se organiza en cuatro partes. En la primera se abordan los planteos y aportes realizados desde la Geografía Histórica, tanto en su tradición más temprana como en las revisiones y renovaciones desarrolladas en las

\footnotetext{
4 En los últimos tiempos se ha desarrollado un extenso debate en torno al estatus de una y otra. Por ejemplo, en cuanto a la Geografía Histórica se discute si se trata de un conjunto de enfoques, una subdisciplina o una perspectiva que atraviesa a toda la Geografía (Norton, 1991; Zusman, 2009). Asimismo con respecto a la Historia Ambiental se discute, entre otras cuestiones, si es un nuevo campo disciplinario, una rama de la Historia o nueva Historia social (Martínez, 1993; Pádua, 2010). En tanto esos debates exceden los objetivos de este artículo, se hace referencia a ellas, de manera genérica, como áreas de estudio.
} 
últimas décadas. La segunda parte se refiere a los planteos de Historia Ambiental, en particular en cuanto a sus orígenes e institucionalización, propuestas programáticas y líneas de indagación. La tercera examina algunas discusiones en torno a ciertos aspectos clave del abordaje histórico de la problemática ambiental realizado desde la Geografía Histórica y la Historia Ambiental actuales. La cuarta y última parte ofrece algunas conclusiones y reflexiones finales.

\section{Aproximaciones a la cuestión ambiental desde la geografía histórica}

Gran parte de los temas que actualmente se reconocen como ambientales han tenido una gran presencia y relevancia en la tradición geográfica, al menos bajo ciertas perspectivas y escuelas. Entre ellos cabe citar, por ejemplo, a la Tierra como morada de la humanidad $y$, sobre todo, a la relación hombre-medio; de hecho, este último ha sido uno de los ejes temáticos nucleares de la tradición e, incluso, el principal entre fines del siglo XIX y mediados del siglo XX (Smith, 1965; Livingstone, 1996). Precisamente en las páginas siguientes se indaga sobre las principales escuelas y obras que han tematizado la cuestión en perspectiva histórica, más precisamente con relación a dos recortes temporales: entre fines del siglo XIX y mediados del siglo XX (es decir, la tradición temprana) y desde la década de 1960 hasta la actualidad (cuando se desarrolla una importante renovación en cuanto a preocupaciones, enfoques y temas en Geografía Histórica).

\section{La cuestión ambiental en la tradición temprana de la geografía histórica}

Se reconocen diferentes e importantes antecedentes sobre la cuestión ambiental bajo un abordaje histórico, básicamente tematizada de manera amplia como relación hombre-medio, incluso antes de la institucionalización moderna de la disciplina.

Sin dudas, una de las figuras más destacadas al respecto es George Perkins Marsh (1801-1882), tanto por su influencia en el desarrollo de la Geografía moderna como en el movimiento conservacionista norteamericano, particularmente a partir de su obra "Man and nature, or physical geography as modified by human action", publicada en 1864 . Este diplomático norteamericano sistematiza allí, "con datos empíricos, las transformaciones que las sociedades humanas han ejercido sobre sus entornos naturales" (Saurí, 1993: 143); así, mediante el análisis de "cuánto era responsable el hombre por la destrucción de su hábitat", discute los planteos acerca de "la influencia de las condiciones físicas externas sobre la vida social y el progreso del hombre", a la vez que promueve un nuevo tipo de historia, comprensiva y social, en la que "la relación de la sociedad con su medio natural es una suma de fuerzas, conflictivas o coincidentes, actuando a través de largas series de generaciones" (Olwig, 1980: 37-38).

Otra figura clave al respecto es Elisée Reclus (1830-1905), geógrafo francés autor de L'Homme et la Terre (1905), entre otras obras. Se destaca por su interés en los procesos por los cuales las sociedades adecuan el medio a sus necesidades y, sobre todo, en las potencialidades restauradoras, más que destructivas, del hombre. Estos temas serían, según Reclus, los que distinguirían a la Geografía Histórica respecto de la Geografía en general: "la Geografía se confina a la descripción de la superficie terrestre y a exhibir las diferentes naciones en una actitud pasiva, mientras que la Geografía Histórica muestra al hombre comprometido en la lucha por la existencia y en el esfuerzo por obtener el dominio sobre su entorno" (Reclus, 1882: 5 cfr. Olwig, 1980: 39-40). Destacado por su pensamiento anarquista, ello también se plasma en sus planteos acerca de la degradación del medio, fundamentalmente en la importancia dada a la alteración del statu quo para restaurar el desbalance de la relación hombre-medio y la necesaria armonización de las relaciones humanas.

Ahora bien, más allá de esos antecedentes, gran parte de la producción geográfica de fines del siglo XIX y primeras décadas del siglo XX se encuentra atravesada por las tesis del determinismo natural; así, la relación hombre-medio es planteada en términos de las influencias que las condiciones naturales ( $y$, en especial, las climáticas) generan en los pueblos, particularmente en 
su grado de progreso o civilización (Livingstone, 1994; Urteaga, 1997). Por su abordaje histórico cabe mencionar la obra del geógrafo norteamericano Ellsworth Huntington, especialmente Civilización y clima (1915). En ella aborda al clima como el factor fundamental para determinar el grado de progreso de los diferentes pueblos debido a sus efectos sobre la alimentación, la salud y, en sucesivas generaciones, sobre las herencias biológica e intelectual ${ }^{5}$; incluso la existencia de grandes civilizaciones en lugares de condiciones climáticas (supuestamente) adversas, como el caso de Grecia, también es explicada a través de ese factor: a partir de la utilización de investigaciones sobre las oscilaciones climáticas, concluye que las condiciones naturales del área eran más aptas (más frías y húmedas) en aquellos tiempos antiguos (Huntington, 1934).

Desde la década de 1930, y como crítica e intento de superación de los planteos deterministas, se consolida al interior de la disciplina el interés por el estudio histórico de la transformación humana de la superficie terrestre. Se trata de un conjunto de autores y obras que, más allá de sus diferencias, enfatizan el rol de la cultura como factor de transformación de las condiciones del medio, configurando un cuerpo de conocimientos que sigue, en parte, los planteos de Marsh y Reclus (Williams, 1994). Entre ellas cabe destacar la obra de la Escuela Regional Francesa, especialmente de Vidal de la Blache y algunos de sus discípulos, de la Escuela de Geografía Cultural de Berkeley, particularmente

\footnotetext{
5 Al respecto afirma que "el clima ocupa el primer puesto [entre los factores que definen el grado de civilización], no porque sea el más importante, sino solamente porque es el más fundamental. Es fundamental a causa de su vital influencia en la cantidad y calidad del alimento del hombre y de la mayoría de sus otros recursos; desempeña un importante papel en la limitación de la distribución y virulencia de los parásitos, que causan la mayor parte de las enfermedades; y mediante su efecto sobre las ocupaciones, modos de vivir y hábitos humanos, se constituye en uno de los principales determinantes de la cultura (...) De todo lo dicho se desprende entonces que si bien el clima no es más importante que otros factores en la fijación del grado relativo de progreso en distintas partes del mundo, es más fundamental en el sentido de que es una causa más bien que un resultado de los otros factores" (Huntington, 1934: 3).
}

en la obra de Carl Sauer, y de la Geografía Histórica británica, sobre todo a través de H.C. Darby.

Además de otras especificidades, la Escuela Regional Francesa puede pensarse como parte de la tradición geográfica que ha abordado lo ambiental en clave histórica en tanto su núcleo temático ha sido la comprensión de las regiones como ámbitos singulares, producto de la relación entre los grupos humanos y su milieu (o ambiente físico y cultural) a lo largo del tiempo (Baker, 2003). En particular su interés se ha concentrado en las técnicas (de cultivo, de drenaje o irrigación, de construcción de viviendas, etc.) como expresión de los modos o géneros de vida conformados a través de aquella relación, una temática que concentra especial interés en aquel momento de transformación de las tradicionales regiones francesas por los procesos de urbanización e industrialización. Una muestra de ese abordaje se encuentra en la serie de monografías regionales elaboradas por Vidal de la Blache y sus discípulos sobre Francia y otros lugares del mundo, especialmente para el proyecto de la Geografía Universal. En particular cabe destacar la obra de Roger Dion, quien se dedicó a producir una geografía histórica rural de Francia, junto a colaboradores como Braudel y otros historiadores de la Escuela de los Annales (Zusman, 2009); entre sus obras se puede señalar el Ensayo sobre la formación del paisaje rural francés (1934), El valle del Loire (1934), La participación de la geografía y la historia en la explicación de la vivienda rural en la cuenca de París (1956) e Historia de la viña y el vino en Francia desde sus orígenes hasta el siglo XIX (1959). Bajo esas influencias también cabe destacar la obra temprana del geógrafo chileno Pedro Cunill Grau, en particular sus trabajos sobre la degradación del paisaje chileno así como sus planteos sobre la elaboración de una geohistoria ${ }^{6}$ latinoamericana (Rodríguez, 2001; Cunill, 2005).

\footnotetext{
6 Remite a la propuesta esbozada por el historiador francés Fernand Braudel, para quien la Geohistoria tenía por objeto el estudio dinámico entre una sociedad del pasado y la estructura geográfica que la sustenta, evidenciada sobre todo a través de la larga duración y la coyuntura.
} 
Como se mencionó previamente, también cabe destacar los estudios realizados en el marco de la Escuela de Geografía Cultural de Berkeley y, en especial, por Carl Sauer, su principal referente; de hecho, algunos autores consideran que el trabajo de Sauer y sus discípulos constituye uno de los componentes más influyentes de la tradición hombre-medio en Geografía Humana (Mathewson, 2011).

En particular la preocupación central de la obra de Sauer es la formación de paisajes culturales; más precisamente, el modelado y modificación de los paisajes naturales por efecto de la cultura, a través del estudio de la relación cambiante entre hábitos y hábitats (Williams, 1994). En su Introducción a la Geografía Histórica, Sauer plantea una serie de temas sobre los cuales la Geografía Histórica debía desarrollar un tipo de conocimiento comparado, que constituirá un legado a la producción de conocimientos sobre la cuestión ambiental; entre ellos se destacan "ciertos procedimientos de Geografía Física que incluyen cambios seculares que afectan al hombre", como los cambios o ciclos climáticos y las alteraciones en la vegetación y en los litorales y drenajes, y el planteo del "hombre como agente de la geografía física", por ejemplo en cuanto a los efectos de la silvicultura en las condiciones climáticas y de los usos del suelo en los cambios geomorfológicos y en la ecología vegetal y animal (Sauer, 1941: 46-47). Siguiendo la propuesta de G. P. Marsh, desarrolla una mirada crítica en cuanto a esa agencia humana sobre los paisajes naturales, en tanto sostiene que "son muchas las formas de desperdicio del capital natural, sus causas son culturales y sus resultados son lentas crisis en las áreas afectadas" (Sauer, 1941: 47); de hecho, uno de sus principales temas de indagación ha sido la transformación del paisaje y sus recursos provocada por la expansión colonial europea, especialmente en cuanto a la difusión de plantas cultivadas y animales domesticados y la erosión de suelos (Sauer, 1938 y 1956)․․

7 Muchos discípulos de Sauer han desarrollado una extensa obra sobre América Latina bajo esas inquietudes y propuestas teórico-metodológicas. Por ejemplo, cabe citar los trabajos realizados en Colombia por James Parsons, acerca de la colonización antio-
Para cumplir esos propósitos, Sauer propone y desarrolla en sus obras una aproximación genética, es decir preocupada por los orígenes y los procesos; su estrategia se concentra en la morfología del paisaje, en particular a través de "la reunión inductiva de hechos acerca del impacto humano en el medio (cómo los paisajes culturales son creados a partir de formas superpuestas al paisaje natural), la construcción del paisaje cultural y los cambios en las formas de vida de las culturas", mediante la utilización de registros de archivos históricos y observaciones de campo $^{8}$ (Sauer, 1941: 36; Smith, 1984).

También para Henry Clifford Darby, una figura dominante en la Geografía Histórica británica de las décadas de 1940 y 1950 , esta área comprendía el estudio de las transformaciones de los paisajes naturales por el hombre. En particular consideraba que "el paisaje humanizado proveía un foco sintético e incontestable para la incorporación del elemento temporal en geografía" (Williams, 1994: 11). Bajo ese interés su obra se concentra en la reconstrucción de geografías pretéritas a través de un análisis de tipo horizontal; más precisamente, su método consiste en la realización de sucesivos cortes en el tiempo en un área dada (cross-sections) con el fin de "sacar conclusiones útiles sobre el relacionamiento del hombre con el medio apoyándose en tales estudios comparativos" (Smith, 1965: 286) ${ }^{9}$. A través del trabajo con fuentes históricas, como datos estadísticos y

queña, y por Robert West, sobre las tierras bajas del Pacífico (Mathewson, 2011; Leal, 2002).

8 Sauer resalta la importancia del trabajo de campo en los estudios de Geografía Histórica. Al respecto señala: "estas observaciones básicas no son mero objeto de biblioteca y archivo, sino también de estudios de campo. Deben ser recogidas las experiencias respecto a la tierra que permanecen en la memoria de la población. La propia tierra puede ofrecer testimonio de valor cronológico, como en el caso de nuestros "antiguos campos" reforestados, donde los anillos de los árboles presentan un importante relato de fechas de abandono de los cultivos. En particular, necesitamos registros de las formas de abuso, de los ciclos viciosos en los que quedan atrapadas las economías destructivas, y de los intentos de la población por liberarse de la situación que ella misma ha creado" (Sauer, 1938: 5).

9 Una reconstrucción que, según aclara Darby, parte del presente: "cada edad mira hacia atrás, hacia las precedentes, con ojos diferentes. Cada edad hace 
cartografías, el sello de su obra fue "la esmerada investigación histórica y, sobre todo, la delineación de los principales procesos de transformación del medio, tales como drenajes, clareos forestales y recuperación de eriales" (Williams, 1994: 11; Zusman, 2009).

La publicación en el año 1956 de la obra Man's role in changing the face of the Earth, editada por W. Thomas en colaboración con C. Sauer, M. Bates y L. Mumford, marca la consolidación académica de los estudios sobre los procesos de transformación de la superficie terrestre por la acción humana. Esa obra, resultado de un simposio internacional realizado en Princeton (EE.UU.) el año anterior y en el que participaron importantes geógrafos (además de Sauer, Darby, Clark y Gourou, entre otros), historiadores, antropólogos y biólogos, tenía por propósito general examinar los efectos de la acción humana sobre la geografía terrestre (tanto con respecto al pasado más lejano como en cuanto a las modificaciones entonces más recientes), así como debatir los límites de la influencia humana sobre la Tierra, con énfasis en la cuestión poblacional, el consumo de materias primas y los efectos tecnológicos.

A lo largo de la primera mitad del siglo $X X$ se va configurando, entonces, un cuerpo de estudios que recoge una preocupación de la época acerca de los signos negativos del "dominio del hombre sobre la naturaleza" y la articula con la discusión sobre el objeto y lugar de la disciplina, así como de la Geografía Histórica en particular. Ahora bien, ello solo tendrá una continuidad acotada y parcial; incluso, algunos autores enuncian la existencia de "una tradición interrumpida" como resultado de diferentes razones: algunas de ellas relativas a las propias limitaciones de esos enfoques, como su gran peso descriptivo (más que interpretativo) y la naturalización del tiempo y el espacio contenida en gran parte de sus planteos; otras razones son relativas a la focalización de la Geografía Histórica en diferentes objetivos, por ejemplo la discusión entre teoría social y estudios empíricos; y otras están vinculadas a la Geogra-

preguntas distintas y la historia tiene que ser reescrita una y otra vez" (Darby, 1984: 238). fía en general, como la mayor difusión de los planteos neopositivistas y la postergación de las temáticas ambientales por parte esos enfoques (Williams, 1994; Norton, 1991; Baker, 2003; Zusman 2009; Sueyer, 2010).

\section{La cuestión ambiental en geografía \\ histórica desde la década de 1960}

Desde la década de 1960 la difusión de problemas ambientales en diferentes lugares del mundo, junto al creciente activismo social al respecto, sobre todo en Estados Unidos y Europa occidental, generan la expansión de esa temática en las Ciencias Sociales en general, aunque más tardíamente en Geografía.

En esa década, además, los estudios de geografía histórica se verán atravesados, como toda la disciplina en general, por una serie de discusiones y aportaciones derivadas en gran medida del rechazo hacia la supuesta objetividad y cientificidad de los enfoques y métodos empleados por las perspectivas cuantitativas y que confluyen, "a grandes rasgos, en dos grandes líneas de pensamiento, el humanismo y el marxismo" (...). De esta manera, "el individuo y la sociedad se vuelven, de pronto, protagonistas en la construcción del espacio y de sus elementos: lo experimentan, lo perciben, lo crean, lo usan, le dan significado y valor al espacio. (...) Y con el individuo y la sociedad, se recupera el lugar y el espacio" (Sunyer Martin, 2010: 151-152).

Una de las primeras incursiones en temas ambientales por parte de esa Geografía Histórica renovada proviene de las perspectivas humanistas y, en particular, de la denominada Geografía de la Percepción. Con base en las filosofías existencialistas y fenomenológicas, esta Geografía se concentra en las pre-concepciones que subyacen a la percepción humana sobre el medio y que atraviesan e influyen sobre las acciones y decisiones llevadas a cabo sobre él a lo largo del tiempo; como bien señala W. Kirk, "así como en la geografía histórica nos interesa la conducta de los grupos humanos en relación con el medio, nos corresponde reconstruir el medio no solo como era en diversas fechas, sino como era observado y se creía que era" (Norton, 1991: 68-69). 
Entre los geógrafos que desarrollaron más tempranamente esa perspectiva cabe destacar a David Lowenthal, en particular por su exploración acerca de las geografías personales (la visión de cada individuo sobre el mundo) y de la influencia de la estructura social, el contexto cultural, la experiencia personal, la imaginación y la memoria en la formación de esas visiones o geografías (Capel, 1973). Por ejemplo, en uno de sus trabajos pioneros, "Geografía, experiencia e imaginación" (1961), plantea que "la superficie de la tierra está modelada por refracción a través de lentes personales de cultura y fantasía para cada persona"; asimismo, señala que esas imágenes individuales del entorno "tienen un curso en el tiempo, una historia propia", y se conformarían como resultado de las experiencias pasadas, es decir que se encuentran atravesadas por el "espejo retardador de (la) memoria" (Lowenthal, 1984: 214-216). Precisamente en sus trabajos posteriores Lowenthal aborda el modo en que funciona la memoria, tanto individual como colectiva, y cómo ella se vincula con los objetos, entre ellos los que se convierten en legado o patrimonio (Sunyer Martin, 2010); por ejemplo, en sus trabajos más recientes indaga sobre la conformación del patrimonio natural, en particular su articulación con el ideario romántico, su distinta definición en las tradiciones norteamericana y europea y, sobre todo, la naturalización de los dispositivos que participan de su selección y activación (Lowenthal, 2005).

Los planteos marxistas en Geografía Histórica también han abordado los temas ambientales, aunque más tardíamente debido al interés prioritario por los procesos sociales en sí, así como por la relegación inicial con respecto a las consideraciones sobre el ambiente físico; incluso lo han hecho como crítica a las perspectivas fenomenológicas, principalmente por soslayar las determinaciones materiales de la realidad social (Williams, 1994; Mathewson, 2011). A partir de su focalización en la dinámica del cambio histórico, con eje en los grupos sociales en conflicto (interpretados como conflictos de clase) y en el espacio como componente activo de las relaciones sociales, estos planteos indagan centralmente en torno a la configuración de desastres ambientales, la depredación de recursos en el marco de los procesos de expansión colonial y capitalista en el Tercer Mundo y, en general, los procesos de producción capitalista de la naturaleza y el rol del Estado como mediador de esas relaciones (Norton, 1991; Saurí, 1993; Williams, 1994; Kearns, 2004); en definitiva, expresan un vuelco o extensión hacia lo ambiental de las exploraciones marxistas sobre la (in)justicia social (Nash, 2000).

Por ejemplo cabe destacar los estudios sobre desastres y riesgos ambientales desarrollados hacia la década de 1970 por Michael Watts, Ben Wisner, Ken Westgate, Phil O'Keefe y otros geógrafos británicos que, bajo un planteo denominado "Economía Política de los Desastres", señalan la necesidad de estudiar las condiciones estructurales (básicamente, políticas y económicas) que determinan esos problemas (Watts, 1983; Lavell, 2005). A partir de este planteo discuten la concepción de los desastres como resultado de fallas en la adaptación de los hombres a los cambios ambientales, propia de la Ecología Humana ${ }^{10}$, para proponer que ellos "más bien dependen del orden social, las relaciones cotidianas ante el hábitat y las amplias circunstancias históricas que moldean o frustran estas cuestiones" (Hewitt, 1983: 25). Se trata de una perspectiva que tendrá una fuerte influencia en los estudios sobre el tema en América Latina, tanto entre geógrafos como otros cientistas sociales, y que, por su fuerte énfasis en las condiciones sociales que definen las situaciones de riesgo ambiental, será conocida como "Escuela de la Vulnerabilidad" (Blaikie et al., 1996; Castro y Zusman, 2009).

También en el marco del pensamiento marxista cabe destacar algunas aproximaciones realizadas por geógrafos anglosajones sobre la relación entre degradación del suelo

\footnotetext{
10 Esta perspectiva, iniciada hacia la década de 1940 en la Universidad de Chicago por Gilbert White, Robert Kates y Ian Burton, plantea a los desastres como resultado de las interrelaciones negativas entre sociedad y ambiente; las mismas estarían originadas en una percepción deficiente del riesgo, ya sea por factores psicológicos y/o socioculturales o por la existencia de conocimientos incompletos, y bajo cuyo marco se vuelve central el concepto de adaptación, es decir la capacidad o habilidad de un grupo social para ajustarse a cambios en su ambiente externo (Saurí, 1993; Lavell, 2005).
} 
y sociedad a lo largo del tiempo. Se trata de una producción realizada más tardíamente, en la década de 1980, y en la que se destacan las obras Political Economy of Soil Erosion in Developing Countries (1985) de Piers Blaikie y Land degradation and society (1987), también de Blaikie junto a Harold Brookfield; en particular a través de esta última desarrollan una perspectiva que denominan Ecología Política Regional (una combinación de las preocupaciones de la Ecología y la Economía Política con los abordajes ambientales y multiescalares de la Geografía), en la que el análisis histórico es central, en parte porque "la degradación no es solo un fenómeno de nuestra época" sino, además, por las "dilaciones o demoras entre las causas y las consecuencias" de esos procesos (Blaikie \& Brookfield, 1991: xxi).

A partir de la década de 1980 cabe destacar, asimismo, otra perspectiva de análisis histórico sobre cuestiones ambientales que, desde los estudios sobre historia de la ciencia e historia de la cultura en general, se centra en el análisis de instituciones y agentes productores de conocimiento ambiental y territorial. Al respecto se destaca el análisis de la influencia de las ideas ilustradas en la gestión de ambientes y recursos, particularmente en el ámbito europeo, siguiendo la tradición de estudios de Clarence Glacken y su obra Huellas en la playa de Rodas. Naturaleza y cultura en el pensamiento occidental desde la Antigüedad hasta finales del siglo XVIII ${ }^{11}$ (Capel, 1980; Urteaga, 1987 y 1997; Casals Costa, 1988). Por ejemplo Urteaga (1987), a partir de la consideración del impacto de la explotación pesquera y la deforestación en España durante el siglo XVIII, examina la preocupación de algunos ilustrados por el

\footnotetext{
${ }^{11}$ Clarence Glacken ha sido un historiador norteamericano que desarrolló gran parte de su vida académica en el Instituto de Geografía de la Universidad de California en Berkeley, bajo la dirección de Carl Sauer (Capel cfr. Glacken, 1997). En la obra citada analiza los cambios en las ideas y actitudes hacia la naturaleza en el marco del pensamiento occidental, desde el Mundo Antiguo hasta fines del siglo XVIII; en particular, examina las relaciones entre cultura y naturaleza en torno a tres cuestiones: el surgimiento y transformación de la idea de una Tierra con un plan o designio divino, la influencia de la naturaleza sobre la sociedad y la acción del hombre como agente transformador de la naturaleza.
}

deterioro del medio y su creencia en la necesidad de una explotación equilibrada de los recursos naturales. Varios trabajos, asimismo, abordan ese tema a través de un tipo de fuente en particular, los relatos de viaje (Freixa, 1999; Naylor, 2001; Castro, 2007); por ejemplo, Consol Freixa (1999) indaga sobre la percepción de los viajeros ilustrados británicos sobre la naturaleza y los paisajes españoles, mientras que Naylor (2001) analiza los relatos del naturalista Guillermo Hudson por la Patagonia a fines del siglo XIX y principios del XX como cruce de las teorías que portaba ese viajero con las características de los paisajes y la naturaleza que encuentra en su recorrido. En el marco más amplio de las historias de las ideas cabe destacar el libro de I.G. Simmons, Interpreting nature (1996), acerca de las construcciones culturales sobre el ambiente en base a diferentes procedencias: las Ciencias Naturales y el conocimiento aplicado o tecnológico, las Ciencias Sociales y las Artes, entre las principales.

También desde la década de 1980, y más activamente desde 1990, se observa en los estudios de geografía histórica abocados a la cuestión ambiental la influencia de perspectivas posestructuralistas, feministas y asociadas al denominado "giro cultural". Ello se evidencia, por ejemplo, en la inclusión de otros actores (las mujeres, los indígenas y los migrantes, entre otros) y de otros ámbitos geográficos, como montañas, humedales y zonas polares, que previamente no eran objeto de atención, así como la interpelación a los saberes y políticas sobre la naturaleza producidos en el pasado (Sunyer, 2010; Nash, 2000; Kearns, 2004). Además de las redefiniciones y ampliaciones temáticas, se observa una serie de aportes epistemológicos y metodológicos. Entre los primeros cabe destacar la discusión acerca de la dicotomía hombre-medio como postulado propio de la Modernidad y habilitador de la explotación de la naturaleza, especialmente de aquella extraeuropea (Castro y Zusman, 2009). Entre los segundos se destacan los planteos acerca de la deconstrucción de las fuentes históricas como descripciones y relatos objetivos para evaluarlas, entonces, como registros sociales e históricos, interrogados desde el presente (Sunyer, 2010). 
Entre los principales estudios signados por estas perspectivas cabe señalar aquellos trabajos centrados en la historia de la construcción de las ideas y las representaciones acerca del ambiente y la naturaleza, fundamentalmente basados en fuentes literarias y visuales (mapas, pinturas, fotografías). Al respecto se destaca la obra de Denis Cosgrove, en particular sus análisis sobre los paisajes como resultado de miradas (es decir, formas de ver e interpretar los lugares) en que se expresan las relaciones de poder (Cosgrove, 2002, 2008; Kearns, 2004).

También cabe destacar los estudios centrados en la producción de ciertas ideas ambientales como dispositivos políticos de control y apropiación de territorios, tributarios en gran medida de los planteos de Edward Said $^{12}$. Es el caso de las investigaciones sobre la noción de desierto, por ejemplo para el caso argentino, que indagan sobre la articulación de prácticas de carácter representacional (en las cuales han tenido un rol clave las sociedades geográficas) con procesos materiales de creación de territorios coloniales y estatalnacionales (Zusman, 1996; Lois, 1999). Asimismo cabe señalar los estudios sobre la idea de tropicalidad en tanto dispositivo que contribuyó a conformar a los trópicos como ámbitos productivos complementarios a Europa (Driver, 2004), o sobre la noción de sertão en Brasil, cuya construcción como ámbito de valoración negativa (vacío, distante, incivilizado) ha apoyado la definición y justificación de prácticas de apropiación y ocupación, así como de localización de infraestructura y objetos técnicos integradores del territorio (Moraes, 2009).

Cabe señalar, finalmente, que esta renovación de perspectivas que registra la Geografía Histórica abocada a cuestiones ambientales no ha conllevado, ni estricta ni ampliamente, el abandono de la tradición más temprana. Por ejemplo, se reconocen numerosos

\footnotetext{
12 Más precisamente en torno a sus planteos sobre el Orientalismo, es decir sobre la red textual que ha ido construyendo a Oriente como una entidad geográfica y cultural diferente a Occidente, extraña $y$, fundamentalmente, inmutable; una estrategia que responde más a la cultura occidental que la produce que a su supuesto objetivo, conocer Oriente (Said, 2002).
}

trabajos, tanto en la Geografía Histórica desarrollada en los Estados Unidos como en la Europa occidental y América Latina, que continúan los planteos histórico-culturales de la Escuela de Berkeley y de la Escuela Regional francesa, en ocasiones articulados con enfoques más recientes. Es el caso de los trabajos de Karl Zimmerer y Alfred Siemens, quienes "representan un puente entre la aproximación tradicional de Berkeley y las nuevas perspectivas de investigación sobre la interacción sociedad-ambiente en Geografía", que fusionan las ciencias ambientales con base en la Ecología Política (Mathewson, 2011: 70). También es el caso de Alfredo Bolsi y sus análisis de las variaciones históricas en la valorización de los recursos naturales y la transformación del paisaje agrario en el nordeste argentino, que retoma el planteo de Sauer acerca de la relación entre hábitos y hábitats (Bolsi, 1995). O de Pedro Cunill Grau, con sus trabajos más recientes en torno a la elaboración de una Geohistoria de la Sensibilidad, a través de la cual articula los planteos braudelianos y los de la Geografía de la Percepción con el objetivo de "investigar la manera en que se ha realizado la percepción del territorio venezolano, definiendo gustos, olores, vistas y sonidos, y en función de lo cual se han "tomado decisiones en la valorización de la biodiversidad y de los recursos naturales, lo mismo que en el disfrute del paisaje" (Cunill, 2005: s/p).

Otros autores retoman la tradición de estudios acerca de las transformaciones de la superficie terrestre por la acción humana y la actualizan con nuevos instrumentos de análisis y visualización de los cambios ambientales y espaciales, especialmente a través de Sistemas de Información Geográfica (SIG). De hecho, Baker (2003) plantea que el mayor desarrollo reciente de la Geografía Histórica se ha dado en tanto estudio de los cambios espaciales a través del tiempo, potenciado precisamente por la aparición y expansión de los SIG.

En síntesis, esta exploración permite observar el peso que las temáticas ambientales han tenido en la tradición más temprana de la Geografía Histórica, así como el reingreso de esa cuestión en las últimas décadas, bajo una variedad de perspectivas teóricas y planteos (muchas de ellas entrecruzadas), por lo general más sensibles a la diferencia social 
y atentas a las relaciones de poder en la conformación de problemas ambientales. Se trata, además, de unos antecedentes que se busca reivindicar de cara a las preocupaciones y demandas por los procesos de deterioro ambiental, así como frente a la expansión de otros campos disciplinarios afines, como la Historia Ambiental (Naylor, 2006).

\section{La emergencia de la historia ambiental: planteos y aportes}

La Historia Ambiental es un campo emergente hacia principios de la década de 1970 interesado, en términos generales, por indagar sobre el rol y el lugar de la naturaleza en la vida humana (Worster, 1994). Surge, bajo esos términos, como una preocupación propia de los historiadores, fundamentalmente para llamar la atención sobre la agencia de la naturaleza en la historia social (Cronon, 1992). Sin embargo, su desarrollo posterior excede ese ámbito para convertirse, sobre todo por su producción y en parte por sus espacios de institucionalización, en un campo interdisciplinario.

\section{Orígenes, institucionalización y antecedentes}

Los relatos acerca del surgimiento de este campo, explícitamente bajo ese rótulo, señalan dos ámbitos: los Estados Unidos y Francia (Worster, 1994; Williams, 1994). Para el primer caso esas definiciones sobre el origen están vinculadas a la figura y la labor de Roderick Nash, un historiador norteamericano reconocido por sus trabajos acerca del rol de la idea de mundo silvestre (wilderness) en la construcción de la identidad nacional; más precisamente se citan la creación de una cátedra bajo esa denominación en la Universidad de California en Santa Bárbara (1972) y la publicación del ensayo The state of enviromental history (1970), donde recomendaba prestar atención al ambiente o entorno como un tipo de documento histórico que revela la cultura y las tradiciones de la sociedad (Williams, 1994). Con respecto a Francia se destacan los trabajos vinculados a la Escuela de los Annales y, muy particularmente, los de Emmanuel Le Roy Ladurie, sobre todo en relación con su obra Historia del Clima desde el año mil (Le Roy Ladurie, 1991); en ella el autor indaga sobre los efectos de los cambios climáticos, sobre todo de la Pequeña Edad Glacial, en la vida de los habitantes de Europa, elaborando, al mismo tiempo, "una introducción metodológica a los problemas que plantea la historiografía del clima reciente en Europa y en América" (Le Roy Ladurie, 1991: 12-13). Más allá de ese origen compartido, es claro el mayor desarrollo de los estudios de Historia Ambiental en los Estados Unidos, tanto en cuanto a producción académica como a espacios de institucionalización; al respecto Baker (2003) sostiene que una posible explicación sobre este dispar desarrollo se deba a la relevancia que para la sociedad norteamericana tiene la conservación del mundo silvestre $y$, consecuentemente, las preocupaciones con relación a su destrucción.

Dos conjuntos de razones habrían incidido, según Padua (2010), al surgimiento de la Historia Ambiental en aquellos años: unas, de carácter sociopolítico y, otras, de tipo epistemológico. Con relación al primer conjunto se destaca la difusión de una serie de estudios a lo largo de las décadas de 1960 y 1970 que alertan sobre el creciente estado de deterioro de los recursos y ambientes del planeta ${ }^{13}$, así como la expansión de ciertas organizaciones sociales y movimientos políticos ambientalistas, entre ellos los denominados Partidos Verdes en Europa occidental. El segundo conjunto de causas remite a una serie de cambios en las formas de conocer y pensar el mundo natural que, si bien ya estaban presentes desde el siglo XIX, se consolidan en la centuria siguiente; en particular se destaca: (a) la revolución en los marcos cronológicos de comprensión del mundo, especialmente a partir de las revisiones sobre la antigüedad del planeta, (b) la sustitución de la concepción de la naturaleza como algo acabado, armónico y estable por otra que la interpreta como materialidades y fuerzas en constante conformación y reconstrucción a lo largo del tiempo, y (c) la idea de que las acciones humanas pueden producir un impacto relevante

\footnotetext{
13 Entre ellos cabe citar a La Primavera Silenciosa (1962) de Rachel Carson, La bomba demográfica (1968) de Paul Ehrlich, La Tragedia de los Comunes (1968) de Garret Hardin y El círculo que se cierra (1971) de Barry Commoner (Coates, 1998).
} 
sobre el mundo natural, incluso al punto de provocar su degradación.

En las décadas siguientes se observa una ampliación de los espacios institucionales en que se desarrolla la Historia Ambiental, tanto por su tipo como por su localización. Una expresión de ello es el surgimiento de asociaciones regionales de Historia Ambiental, entre las que cabe destacar a la American Society for Environmental History (ASEH), creada en 1977 y a cargo de la publicación de la revista Environmental Review (luego Environmental History Review); la European Society for Environmental History (ESEH), creada en la década de 1990; y la Sociedad Latinoamericana y Caribeña de Historia Ambiental (SOLCHA), gestionada desde el 2003 y formalizada como tal en el año 2006, la cual edita desde el año 2011 la revista Historia Ambiental Latinoamericana y Caribeña.

En este proceso de conformación de la Historia Ambiental como campo académico se señala a una serie de autores, escuelas y obras como antecedentes o precursores. En especial se destaca la Escuela de los Annales y, sobre todo, la obra de Fernand Braudel, a través de las cuales "generaciones de historiadores han aprendido la importancia de la larga duración y de la cultura material, del clima y de la comida, de los métodos agrícolas y de la construcción de los espacios, entre otros. El legado de los Annales y la importancia de sus planteamientos como matriz cultural y metodológica para la historia ambiental es quizá de las pocas cuestiones que no genera debate entre los historiadores, cualesquiera sea su pertenencia cultural y nacional (Gallini, 2002: 3). Otros autores reconocen, además, la importancia de los estudios en Historia de las Civilizaciones, principalmente, los trabajos de Arnold Toynbee y Lewis Mumford, así como la tradición en Antropología Cultural, sobre todo a través de las obras de Julian Steward y Marshall Sahlins (Worster, 1994; Drummond, 1991). En cuanto a la producción geográfica se destacan, principalmente, los trabajos de Carl Sauer con respecto al hombre como agente de la geografía física (Worster, 1994) y, en el de caso de la producción realizada en América Latina, a Pedro Cunill Grau, entre otros (Clare, 2009); también, la obra de Clarence Glacken, un historiador norteamericano que desarrolló gran parte su vida académica en el Instituto de Geografía de la Universidad de California en Berkeley, en particular sus trabajos acerca de la historia de las ideas sobre la naturaleza en el mundo occidental desde la Antigüedad hasta el siglo XX (Capel cfr. Glacken, 1997).

\section{Aportes, debates y programas}

A lo largo de las últimas cuatro décadas se ha desarrollado una vasta producción en Historia Ambiental, sobre todo en los Estados Unidos, Australia y América Latina ${ }^{14}$. Son emblemáticos, por ejemplo, los estudios de Donald Worster, como Dust Bowl: the southern plains in the 1930s (1982), sobre las tempestades de polvo que asolaron las planicies centrales de Estados Unidos de América en la década de 1930, y Rivers of empire. Water, aridity and growth of the American West (1985), acerca de las alianzas entre ciertas dependencias estatales y grandes productores agrícolas para la transformación del Oeste norteamericano por medio de obras hidráulicas. También los trabajos de William Cronon, como Changes in the land: indians, colonists and the ecology of New England (1983), sobre los cambios del paisaje de Nueva Inglaterra (Estados Unidos) en tiempos coloniales por parte de los pueblos indígenas y los colonos europeos en relación con los regímenes de tenencia de la tierra, entre otras instituciones sociales, y Nature's Metropolis: Chicago and the Great West (1991), centrado en las transformaciones que impone la expansión de la ciudad de Chicago en su hinterland rural durante la segunda mitad del siglo XIX. Otro autor destacado es Alfred Crosby que ha desarrollado una importante línea de investigación acerca de la difusión y expansión de plagas, malezas y virus como componentes del éxito de la conquista y coIonización europea sobre las "Nuevas Américas" (América, Australia y Nueva Zelanda), tema abordado en sus libros The Columbian Exchange: biological and cultural consequences of 1492 (1972) e Imperialismo ecológico.

\footnotetext{
14 En los últimos años se ha elaborado una serie de estados de la cuestión que precisan y amplían los lineamientos señalados aquí; entre otros cabe destacar a Drummond (1991), Radkau (1993), Williams (1994), Stewart (1998), Castro Herrera (2005), Clare (2009) y Pádua (2010).
} 
La expansión biológica de Europa, 900-1900 (1986). También cabe destacar algunas obras que se concentran, más específicamente, en el análisis de las ideas acerca de la naturaleza y las prácticas sociales y territoriales articuladas a ellas. Es el caso de los libros de Donald Worster sobre la historia de las ideas ecológicas (The weath of nature, 1993) y de Keith Thomas sobre los cambios en las actitudes hacia las plantas y animales en Inglaterra entre los siglos XVI y XIX (O homem e o mundo natural. Mudancas de attitude em relacao as plantas e aos animais, 1500-1800, 1983), así como de David Arnold y sus trabajos acerca de la idea de tropicalidad, más precisamente sobre la idea de los trópicos como ámbitos extraños y de degradación moral con la que se justificaron políticas de colonización (The problem of nature: environment, culture and European expansión, 1996).

En los últimos años también se viene desarrollando una extensa producción sobre América Latina, en gran medida por autores de la región, alimentada por diferentes antecedentes e inspiraciones: la producción anglosajona sobre el tema, los precursores de la región (como Pedro Cunill), los estudios de la CEPAL de la década de 1980 sobre estilos de desarrollo e, incluso, la obra de intelectuales y periodistas clave del pensamiento latinoamericano, desde José Martí a Eduardo Galeano (Castro Herrera, 2005; Clare, 2009). Entre otros, y solo a modo de ejemplo, cabe citar la compilación de Fernando Ortiz Monasterio sobre historia ambiental de México (Tierra profanada: Historia ambiental de México, 1987), así como los trabajos de Prieto y Abraham sobre el proceso de desertificación de las planicies cuyanas (Historia ambiental del sur de Mendoza - siglos XVI al XIX, 1998) y de Pablo Camus Gayán sobre la percepción y administración de los bosques en Chile en el largo plazo (Ambiente, bosques y gestión forestal en Chile, 1541-2000, 2006); en relación con las ideas ambientales cabe destacar a José Augusto Pádua, en particular su trabajo sobre la formación de una reflexión crítica en torno al problema de la destrucción del ambiente natural en Brasil entre fines de los siglos XVIII y XIX, a través de la cual pone en discusión la idea de la cuestión ambiental como un debate reciente e importado ( $U m$ sopro de destruição. Pensamento político e crítica ambiental no Brasil escravista, 1786-
1888, 2002). También cabe señalar una destacada obra sobre América Latina realizada por autores no latinoamericanos, como Warren Dean (With broadax and firebrand. The destruction of the Brazilien Atlantic Forest, 1995), Elinor Melville (Plaga de ovejas. Consecuencias ambientales de la conquista de México, 1994) y John Soluri (Banana cultures: agriculture, consumption, and environmental change in Honduras and the United States, 2005).

En atención a las temáticas desplegadas en los estudios de Historia Ambiental se reconoce una serie de líneas de investigación predominantes: a) cómo las sociedades dependen del ambiente o entorno natural para sostener sus existencias y cómo han sido afectadas por él, b) cómo las sociedades han modificado los paisajes en que viven y trabajan y con qué consecuencias (para ellas y esos ambientes), c) cómo las ideas sobre la naturaleza moldean las relaciones de los grupos sociales con el mundo que los rodea (Cronon, 1992; Worster, 1994).

Ahora bien, una parte importante de los estudios en este campo está centrada en la segunda línea temática, es decir en las modificaciones e impactos de las acciones humanas sobre el ambiente natural, y, sobre todo, en el análisis de los problemas ambientales como resultado del proyecto iluminista moderno y capitalista de dominio de la naturaleza por medio de la ciencia y la técnica; más precisamente, se trata de una línea temática que se organiza como crítica a los efectos ambientales y sociales de ese proyecto (Baker, 2003; Padua, 2010). No obstante el valor académico y sociopolítico de estos estudios y planteos, algunos autores señalan que la Historia Ambiental debe ser algo más que el inventario y análisis de "los males infligidos por los seres humanos al planeta" (Cronon, 1993; Arnold, 2001; Gallini, 2002; Pádua, 2010). En particular, plantean que frente a las hegemónicas narrativas modernas "progresivas", que solo señalaban las transformaciones del medio como epopeyas civilizatorias ${ }^{15}$, se ha desarrollado un con-

\footnotetext{
15 Al respecto uno de los ejemplos más citados -y confrontados- es el de las historias de la frontera nortea-
} 
junto de relatos "regresivos", organizados en torno a la idea de retroceso ambiental, que va desde las culturas aborígenes hasta la crisis ecológica actual ${ }^{16}$; Gallini (2002) alude a este tipo de interpretación como una "teoría de los estadios de la decadencia ambiental", parafraseando -en sentido inverso- la tesis de Rostow sobre las etapas o estadios de crecimiento económico. Entre otras cuestiones se discute esa visión por su carácter excluyentemente catastrofista, que parte de la asunción de una supuesta "edad de oro" (los tiempos premodernos, las culturas indígenas); frente a ello se plantea, a su vez, la necesidad de indagar a los grupos humanos como creadores, y no solo destructores, sin predeterminar el sentido de las relaciones (Padua, 2010).

Finalmente, ¿cómo hacer Historia Ambiental? El principal planteo programático al respecto ha sido esbozado por Donald Worster, uno de los historiadores ambientales más reconocidos e influyentes. En particular señala que la realización de estudios en ese campo comprende tres niveles de indagación, a los que tributarían diferentes disciplinas: la comprensión de la naturaleza misma, en particular cómo estaba organizada y funcionaba en tiempos pasados; el análisis del dominio socioeconómico en su interacción con el ambiente; y, por último, el estudio de las ideas y otras estructuras de significado que forman parte del diálogo individual o grupal con la naturaleza (Worster, 1994).

En particular, el primer nivel de indagación trata sobre la necesidad de entender la propia dinámica natural como requisito para conocer las causas, características y efectos de las transformaciones ambientales; se reconocen al respecto los aportes realizados, particularmente, desde la Ecología por su mayor desarrollo en cuanto a metodología y fuentes de análisis. El segundo nivel aborda cómo,

mericana, como la de Frederick J. Turner (El significado de la frontera en la historia americana, 1893).

16 El libro de Clive Ponting (Historia verde del mundo, 1992) es un ejemplo de esa narrativa. Se trata de una revisión de la historia mundial (aunque fundamentalmente solo se centra en las experiencias europea y norteamericana) en la que se analizan los efectos ambientales de la expansión de la agricultura sedentaria y los asentamientos humanos, así como del desarrollo de la industrialización, en tanto causas básicas de la moderna degradación ambiental. a través de la tecnología, las sociedades han convertido a la naturaleza en productora de recursos para satisfacer sus necesidades, tanto de producción como de reproducción social; comprende el estudio de las herramientas y el trabajo, las relaciones sociales, las instituciones sociales, los roles de género y las configuraciones de poder que afectan la toma de decisiones sobre el ambiente. La tercera línea focaliza el interés sobre las percepciones, valores, normas, mitos y otras representaciones que las sociedades (o grupos sociales) construyen sobre la naturaleza, partiendo de entender que "la naturaleza es un orden y un proceso que no creamos y que continuará existiendo en nuestra ausencia (pero que), al mismo tiempo, es también una creación de nuestras mentes" (Worster, 1994: 302). Los estudios más logrados (o más acabadamente de Historia Ambiental) serían, según ese autor, aquellos que desarrollan las tres líneas de manera combinada y dinámica.

Este planteo programático ha recibido algunas críticas. Entre ellas, la escasa discusión acerca de las cuestiones de poder y género (Cronon, 1992); también, la consideración de la Ecología como fuente para las potenciales teorías y datos sobre la naturaleza, en particular, de la "vieja Ecología", organizada en torno a la idea de equilibrio o balance de la naturaleza (Demeritt, 1994). No obstante ello, se trata de un planteo que continúa siendo un referente importante en la Historia Ambiental, en tanto ha otorgado ciertas bases y cohesión a esos estudios.

\section{Contribuciones y discusiones compartidas}

Si bien en los últimos años la Geografía Histórica ambiental y la Historia Ambiental presentan una serie de preocupaciones propias (por ejemplo, en torno a recuperar una tradición, en el caso de la primera, y en cuanto a consolidar el campo, en el caso de la segunda), también se observan diversas contribuciones teóricas y metodológicas que cruzan a una y otra, y que interesa recuperar para los debates específicos de la Geografía Histórica actual.

Entre ellas cabe señalar los debates acerca de la integración de conocimientos producidos desde las Ciencias Naturales y las 
Ciencias Sociales y, junto a ello, la búsqueda de enfoques menos dualistas y dicotómicos. También cabe destacar los planteos acerca de las fuentes relevantes para el estudio histórico de cuestiones ambientales, los requisitos para su utilización y las técnicas para su análisis. Otros temas en discusión se refieren a las unidades de análisis más pertinentes y al rol de la estructura narrativa (Drummond, 1991; Cronon; 1992; Radkau, 1993; Demeritt, 1994; Branstroom, 2004; Gallini, 2004; Clare, 2009; Pádua, 2010); nos detendremos sobre estas dos últimas cuestiones en las líneas siguientes.

En particular, las proposiciones acerca de la unidad de análisis en este tipo de estudios transitan por dos discusiones: las relativas a la dimensión del área y las referidas a su delimitación. Con respecto a la primera discusión se señala que los estudios históricos sobre la cuestión ambiental suelen ser planteados en torno a dos extremos: análisis de acontecimientos circunscriptos a áreas pequeñas o indagaciones de procesos globales, que involucran al planeta (o a gran parte de él) como ámbito de referencia. Algunos autores señalan que esas unidades pequeñas, locales, son los ámbitos de referencia más adecuados para este tipo de estudios; por ejemplo, Arnold (2001: 14) sostiene que si bien "es posible escribir una historia ambiental que se ocupe de un solo país o una sola región, quizás sea en el propio nivel local donde el historiador pueda identificar satisfactoriamente los muchos factores -clima, suelo, cultivos, vida animal, etc.- que forman parte de una historia ambiental más compleja" Radkau (1993), en cambio, retoma aquella distinción anterior, a la que formula como "microhistorias" versus "vuelos de altura", y plantea las potencialidades y limitaciones de cada una de ellas, en particular con respecto a la elaboración teórica que se deriva de uno y otro tipo de estudios. En particular sostiene que "el lema paradójico del movimiento ecológico (pensar de forma global, actuar in situ) se refleja también en el panorama actual de la historia del medio ambiente. Las reflexiones teóricas se mueven normalmente siempre a varios niveles superiores a las investigaciones empíricas. Dicho con un poco de malicia: por una parte, tenemos el tipo A de la historia humanista del medio ambiente; se trata del tipo olímpico de los vuelos de altura de la historia global, y, por la otra, está el tipo B, (...) la historia de la contaminación del arroyo $X$ por la fábrica $Y(\ldots)$; ambos tipos tienen sus deficiencias y si uno las perpetúa eternamente se acaba en un callejón sin salida. Los vuelos de altura por la historia de las ideas no consiguen captar verdaderamente el desarrollo real de las relaciones entre humanidad y medio ambiente, ya que esta historia real tiene mucho más que ver con las costumbres diarias de las masas que con las ideas de los grandes espíritus (...). Sin embargo, también el tipo B tiene sus límites: se queda con facilidad estancado en una historia puntual y narrativa" (Radkau, 1993: 128-129).

Otra discusión, relacionada con la anterior, remite a los criterios de delimitación de las unidades espaciales de análisis, particularmente en cuanto a no cerrar o acotar las indagaciones en torno a los ámbitos estatales (Radkau, 1993; Arnold, 2001; Gallini, 2004). Este tipo de planteo, formulado especialmente por historiadores ambientales, es elaborado como crítica a los estudios históricos tradicionales, circunscriptos por lo general al estado nacional y sus divisiones políticoadministrativas (provincias, estados, departamentos, municipios, etc.). Los estudios histórico-ambientales, en cambio, exigirían la consideración de otros recortes, acordes a las dinámicas y los procesos bajo estudio, especialmente para captar aquellos naturales (climáticos, geomorfológicos, hidrológicos, biológicos, etc.); por ejemplo Arnold (2001: 14) plantea al respecto que, "como nos lo recuerdan el 'calentamiento global' y otros fenómenos de alcance planetario, la historia ambiental también debe ver más allá de las antiguas fronteras geográficas que durante mucho tiempo han regido nuestras maneras de abordar la historia".

Si bien algunos autores señalan que aún hay razones prácticas y teóricas para que estos estudios sigan refiriéndose a las tradicionales delimitaciones espaciales ${ }^{17}$, cada vez vienen siendo más frecuentes los estudios a

\footnotetext{
17 Las motivaciones prácticas se vinculan con las fuentes y sus lugares de conservación (muchas de ellas asociadas a jurisdicciones político-territoriales); las razones teóricas se deben a la relevancia histórica de ciertos espacios, como el territorio estatal-nacio-
} 
nivel de cuencas hidrográficas, biomasa, montañas, valles, etc. Estas definiciones siguen, en gran medida, la propuesta de Worster (1994) acerca del ecosistema como unidad privilegiada de análisis en Historia Ambiental, o la de Drummond (1991), que privilegia a la región definida según criterios de homogeneidad natural. Incluso algunos autores plantean la necesidad de promover un nuevo tipo de estudios regionales, el "biorregionalismo", que atienda la particularidad de los lugares como resultado de la interpenetración de la cultura humana con la diversidad de topografías, climas, ecologías (Stewart, 1998).

Si bien resulta enriquecedor el planteo de repensar las tradicionales unidades espaciales de análisis, también cabe señalar algunos riesgos y desafíos al respecto. En ese sentido desde la Geografía, y en particular desde los estudios territoriales (Sack, 1986; Haesbaert, 2005), cabe recuperar la discusión acerca del rol de las instituciones y los agentes políticos y económicos en la producción social del espacio $y$, por tanto, el riesgo de invisibilizar esas actuaciones al definir unidades y recortes desde la lógica de los procesos naturales.

Otro de los debates y contribuciones sobre la cuestión se relaciona con la organización (y el poder) de la estructura narrativa. En particular los estudios históricos sobre la cuestión ambiental asumen, precisamente en tanto historias, una forma narrativa, es decir, involucran una trama desarrollada a lo largo del tiempo, con un comienzo y un fin, en la que se despliegan actores (humanos, no humanos), prácticas y procesos. Ahora bien, los componentes centrales de la estructura narrativa (dónde comienza y dónde termina la historia, qué actores, prácticas y procesos se incluyen y visualizan y cuáles no) constituyen una cuestión central: de ella se derivan conclusiones con las que se juzgan sujetos, procesos y eventos e, incluso, se definen políticas (Cronon, 1992; Baker, 1997). Tal como se planteó previamente, este es un tema crucial para el abordaje histórico de cuestiones ambientales a fin de evitar caer en aquella dicotomía "historias progresivas" versus "his-

nal, en particular para ciertas líneas temáticas de historia ambiental (Gallini, 2004). torias regresivas" y propiciar, a su vez, la producción de estudios comprensivos, que den cuenta de las mediaciones y los matices, sin predeterminar las secuencias.

En ese sentido uno de los planteos que se viene desarrollando, tanto por historiadores como por geógrafos históricos, se refiere a cómo definir los componentes de la narración: ¿de qué manera proceder?, ¿en base a qué criterios? Al respecto, Cronon (1992) propone una estructura tripartita de reglas e instituciones para este tipo de estudios; en particular señala que los componentes a seleccionar e incorporar: a) no deben contravenir los hechos conocidos sobre el pasado, b) tienen que tener sentido ecológico, y c) deben corresponder a las normas de trabajo establecidas como tales por su comunidad.

Esta propuesta de Cronon tiene la ventaja de explicitar criterios de selección y, en parte, poner en evidencia que los datos y conclusiones elaborados se establecen conforme pautas y criterios relativos de verdad. En particular esto es planteado en el ítem c) con respecto a la consideración de las normas comunitarias a las que pertenece cada investigador; por ejemplo, Cronon se reconoce como miembro de diversas comunidades en su carácter de historiador, hombre blanco de clase media-alta y ambientalista, cuyas normas participarían -directa o indirectamente- de su perspectiva y de sus elecciones. Sin embargo, estas observaciones no son aplicadas a los dos primeros criterios: allí, siguiendo una epistemología realista, señala a los "hechos conocidos sobre el pasado" y al "sentido ecológico" como repositorios de verdades (Demeritt, 1994). En efecto, los "hechos históricos" son construidos por una particular comunidad discursiva (los historiadores, los geógrafos históricos, entre otros), al igual que los "hechos sobre la naturaleza" (por los científicos naturales, y no solo por la Ecología); ambos, por tanto, son históricamente contingentes.

¿Cómo abordar el dilema de la estructura narrativa, entonces? En principio reconociendo y asumiendo que los ejes, las variables, los datos y las conclusiones elaborados se establecen conforme pautas y criterios relativos, y no absolutos, de verdad (o, más precisamente, de validez); es decir, evitando mirar 
a la Historia como espejo de los "hechos del pasado" y a la Ecología y las Ciencias Naturales en general como espejos de la naturaleza. Junto a ello también se plantea la importancia de la elaboración de narrativas ambientales lo más inclusivas posibles, sobre todo en cuanto a actores, procesos, problemas y escalas, que otorguen herramientas más efectivas para una lectura crítica de nuestro mundo, presente y pasado (Demeritt, 1994; Nash, 2000).

\section{Reflexiones finales}

Más allá de sus diferentes orígenes disciplinarios y trayectorias, la Geografía Histórica y la Historia Ambiental presentan actualmente un conjunto de intereses y planteos en común con relación a la cuestión ambiental. Fundamentalmente ambas vienen contribuyendo a la recuperación, para los estudios históricos, del sentido de "la agencia, autonomía y materialidad de la naturaleza", sin por ello caer en planteos deterministas o en prescripciones morales (Nash, 2000: 27). Incluso desarrollan una tensión entre la consideración de las mediaciones sociales y culturales que participan de nuestra aproximación a la naturaleza y el reconocimiento de que se trata un dominio o esfera que es más que su construcción humana (Pádua, 2010). Ello se articula además, en el caso de la Geografía Histórica, con un recorrido que parte de la relación hombre-medio y avanza, bajo diferentes perspectivas y estrategias, en la problematización de "lo humano" y de "lo ambiental".

Como hemos visto, también se trata de áreas de estudio con una fuerte dimensión crítica, en particular hacia los efectos ambientales y sociales del colonialismo y el capitalismo moderno, así como hacia la mirada idealizada de las sociedades premodernas y precoloniales (Nash, 2000). Precisamente por el compromiso por atender problemas, comprender sus causas y promover su solución o reducción, algunos autores plantean que estos estudios contienen una importante dimensión ética (Cronon, 1992; Aguilar-Robledo y Torres-Montero, 2005).

La exploración realizada a lo largo de las páginas previas permite evidenciar, finalmente, que se ha ido configurando un cam- po fértil de estudios para el debate sobre la cuestión ambiental en perspectiva histórica y que, en el caso de la Geografía Histórica latinoamericana, tiene un largo camino aún por recorrer en cuanto a pensar y construir herramientas para los problemas y desafíos propios de la región.

\section{Referencias bibliográficas}

AGUILAR-ROBLEDO, M. Formation of the Miraflores Hacienda: Lands, Indians, and Livestock in Eastern New Spain at the End of the Sixteenth Century. Journal of Latin American Geography, 2003, Vol. 2, No 1, p. 87-103.

AGUILAR-ROBLEDO, M. y TORRESMONTERO, M. Ambiente y cambio ambiental: ¿ejes para deconstruir y (re)construir a la historia ambiental? Vetas. Revista de El Colegio de San Luis, 2005, Año VII, Nº 19, p. 9-33.

ARNOLD, D. La naturaleza como problema histórico: el medio, la cultura y la expansión de Europa. México: Fondo de Cultura Económica, 2001.

BAKER, A. Geography and History. Bridging the divide. Cambridge: Cambridge University Press, 2003.

BLAIKIE, P. \& BROOKFIELD, H. Land degradation and society. New York: Routledge, $2^{\circ}$ ed., 1991.

BLAIKIE, P.; CANNON, T.; DAVIS, I. y WISNER, B. Vulnerabilidad: el entorno social, político y económico de los desastres. Bogotá: Tercer Mundo Editores, 1996.

BOADA, M. y SAURÍ, D. El cambio global. Barcelona: Rubes Editorial, 2002.

BOLSI, A. Sociedad, naturaleza y equidad social. Actas I Congreso en Investigación en Ciencias Sociales. San Miguel de Tucumán: Universidad Nacional de Tucumán, 1995, p. 183-187.

BRANNSTROM, C. What kind of history for what kind of political ecology? Historical Geography, 2004, Vol. 32, p. 71-87. 
CAMUS, P. Ambiente, bosques y gestión forestal en Chile, 1541-2005. Santiago de Chile: Ediciones de la Dirección de Bibliotecas, Archivos y Museos, 2006.

CAPEL, H. Percepción del medio y comportamiento geográfico. Revista de Geografía, 1973, Vol. VII, No 1, p. 58-150.

CAPEL, H. Organicismo, fuego interior y terremotos en la ciencia española del XVIII. GeoCrítica, 1980, Año XII, Nº 27-28, Disponible en Internet: http://www.ub.edu/geocrit/ geo27-28.htm.

CASALS, V. Defensa y ordenación del bosque en España. Ciencia, naturaleza y sociedad en la obra de los Ingenieros de Montes durante el siglo XIX. Geocrítica, 1988, $\mathrm{N}^{\circ}$ 73, Disponible en internet: http://www www. ub.edu/geocrit/geo73.htm

CASTRO, H. Otras miradas, otros lugares. Viajeros científicos por el Noroeste argentino. En: ZUSMAN, P.; LOIS, C. y CASTRO, H. (compiladoras). Viajes y geografías. Turismo, migraciones y exploraciones en la construcción de lugares. Buenos Aires: Editorial Prometeo, 2007, p. 93-113.

CASTRO, H. Naturaleza y ambiente. Significados en contexto. En: GUREVICH, R. (compilador). Ambiente y educación. Una apuesta al futuro. Buenos Aires: Editorial Paidós, 2011, p. 43-74.

CASTRO, H. y ZUSMAN, P. Naturaleza y cultura: ¿dualismo o hibridación? Una exploración por los estudios sobre riesgo y paisaje desde la Geografía. Investigaciones Geográficas, 2009, No 70, p. 135-153.

CASTRO, G. De civilización y naturaleza. Notas para el debate sobre la historia ambiental latinoamericana. Polis-Revista de la Universidad Bolivariana, 2005, Vol. 4, № 10, p. 2-11.

CLARE, P. Un balance de la historia ambiental latinoamericana. Revista Historia, 2009, No 59-60, p. 185-201.

COATES, P. Nature. Western attitudes since ancient times. Berkeley: University of California Press, 1998.
COSGROVE, D. Observando la naturaleza: el paisaje y el sentido europeo de la vista. Boletín de la Asociación de Geógrafos Españoles, 2002, N³4, p. 63-89.

COSGROVE, D. Images and imagination in 20th-century environmentalism: from the Sierras to the Poles. Environment and Planning A, 2008, Vol. 40, p. 1862-1880.

CRONON, W. A place for stories: nature, history and narrative. The Journal of American History, 1992, Vol. 78, N 4, p. 1347-1376.

CRONON, W. The uses of Environmental History. Environmental History Review, 1993, Vol. 17, N³, p. 1-22.

CROSBY, A. Imperialismo ecológico. La expansión biológica de Europa, 900-1900. Barcelona: Editorial Crítica, 1988.

CUNILL, P. Las transformaciones del espacio geohistórico latinoamericano, 1930-1990. México: Fondo de Cultura Económica, 1995.

CUNILL, P. Ensoñación y combate por la geografía histórica y regional iberoamericana. Scripta Nova. Revista electrónica de Geografía y Ciencias Sociales, 2005, Vol. IX, No 194 (120), Disponible en Internet:

http://www.ub.es/geocrit/sn/sn-194-120.htm

DARBY, H.C. The clearing of the woodland in Europe. In: THOMAS, W. (editor), Man's role in changing the face of the Earth. Chicago: The University of Chicago Press, 1956, p.183-215.

DARBY, H.C. El problema de la descripción geográfica. In: RANDLE, P. H. Teoría de la Geografía, Vol. 2, Buenos Aires: GAEAOIKOS, 1984, p. 231-251.

DEMERITT, D. Ecology, objectivity and critique in writings on nature and human societies. Journal of Historical Geography, 1994, Vol. 20, N¹, p. 22-37.

DRIVER, F. Imagining the tropics: views and visions of the tropical world. Singapore Journal of Tropical Geography, 2004, Vol. 25, $\mathrm{N}^{\circ} 1$, p. 1-17. 
DRUMMOND, J. A historia ambiental: temas, fontes e linhas de pesquisa. Estudos Históricos, 1991, Vol. 4, № 8, p. 177-197.

ESTENSSORO, F. Antecedentes para una historia del debate político en torno al medio ambiente: la primera socialización de la idea de crisis ambiental (1945-1972). Universum, 2007, Vol. 22, No 2, p. 88-107.

FREIXA, C. Imágenes y percepción de la naturaleza en el viajero ilustrado. Scripta Nova. Revista electrónica de Geografía y Ciencias Sociales, 1999, № 42, Disponible en Internet: http://www.ub.edu/geocrit/sn-42.htm

GALLINI, S. Invitación a la Historia Ambiental. Cuadernos Digitales, 2002, Vol. 6, Nº 18. Disponible en Internet: http://ns.fcs.ucr. ac.cr/ historia/cuadernos/c18-his.html

GALLINI, S. Problemas de métodos en la historia ambiental de América Latina. Anuario IHES, 2004, No 19, p. 147-171.

GARCÍA, B. y PRIETO M.R. (compiladores). Estudios sobre historia y ambiente en América. Tomo II. México: El Colegio de México-IPGH, 2002.

GLACKEN, C. Huellas en la playa de Rodas. Naturaleza y cultura en el pensamiento occidental desde la Antigüedad hasta finales del siglo XVIII. Barcelona: Ediciones del Serbal, 1997.

HAESBAERT, R. Da desterritorialização à multiterritorialidade. Anais do X Encontro de Geógrafos da América Latina. São Paulo: Universidade de São Paulo, 2005, p. 6.7746.792 .

HEWITT, K. The Idea of Calamity in a Technocratic Age. In: HEWITT, K. (editor). Interpretations of Calamity, from the viewpoint of Human Ecology. London: Allen and Unwin, 1983, p. 3-32.

HEWITT, K. Daños ocultos y riesgos encubiertos: haciendo visible el espacio social de los desastres. En: MANSILLA, E. (editor). Desastres: modelo para armar. Colección de piezas de un rompecabezas social. Lima: La Red, 1996, p. 1-29.
HUNTINGTON, E. Civilización y clima. Madrid: Revista de Occidente, 1934.

KEARNS, G. Environmental History. In: DUNCAN, J.; JOHNSON, N. \& SCHEIN, R. (Editores). A companion to Cultural Geography. Okford: Blackwell Publishing, 2004, p. 194-208.

LAVELL, A. Los conceptos, estudios y práctica en torno al tema de los riesgos y desastres en América latina: evolución y cambio, 1980-2004. San José de Costa Rica: FLACSO, 2005. Disponible en Internet: http:// bibliotecavirtual.clacso.org.ar/ar/libros/flacso/ secgen/lavell.pdf

LE ROY LADURIE, E. Historia del clima desde el año mil. México: Fondo de Cultura Económica, 1991.

LEAL, C. La naturaleza en los estudios sociales. En: PALACIO, G. y ULLOA A. (editores). Repensando la naturaleza. Bogotá: ICANH/Colciencias, 2002, p. 123-137.

LIVINGSTONE, D. The Geographical Tradition. Episodes in the History of a Contested Enterprise. Cambridge: Blackwell Publishers, 1996.

LOIS, C. La invención del desierto chaqueño. Una aproximación a las formas de apropiación simbólica de los territorios del Chaco en los tiempos de formación y consolidación del estado nación argentino. Scripta Nova. Revista electrónica de Geografía y Ciencias Sociales, 1999, № 38. Disponible en Internet: www.ub.es/geocrit/sn-38.htm.

LOWENTHAL, D. Geografía, experiencia e imaginación. En: RANDLE, P.H. Teoría de la Geografía, Vol. 2. Buenos Aires: GAEAOIKOS, 1984, p.189-229.

LOWENTHAL, D. Natural and cultural heritage. International Journal of Heritage Studies, 2005, Vol. 11, No 1, p. 81-92.

MARSTON, S. The social construction of scale. Progress in Human Geography, 2000, Vol. 24, No 2, p. 219-242. 
MARTÍNEZ, J. Temas de historia económica-ecológica. En: GONZÁLEZ DE MOLINA, M. y MARTÍNEZ, J. (editores). Historia y ecología. Madrid: Marcial Pons Editores, 1993, p. 19-48.

MASSEY, D. Questions of locality. Geography, 1993, Vol. 78, N², p. 142-149.

MATHEWSON, K. Sauer's Berkeley School legacy: foundation for an emergent Environmental Geography? En: BOCCO, G., URQUIJO, P. y VIEYRA, A. (coordinadores). Geografía y ambiente en América Latina. México: Centro de Investigaciones en Geografía Ambiental - Universidad Nacional Autónoma de México, 2011, p. 52-81.

MCKIBBEN, B. El fin de la naturaleza. Barcelona: Plaza y Janés, 1990.

MORAES, A. Geografía histórica do Brasil. Cinco ensaios, uma proposta e uma crítica. São Paulo: AnnaBlume, 2009.

MUSSET, A. Mudarse o desaparecer. Traslado de ciudades hispanoamericanas y desastres (siglos XVI-XVIII). En: GARCÍA ACOSTA, $\mathrm{V}$. (coordinadores). Historia y desastres en América Latina. Vol. I. Bogotá: La Red- CIESAS, 1996, p. 41-69.

MUSSET, A. Lo sano y lo malsano en las ciudades españolas de América (siglos XVI-XVII). En: GARCÍA, B. y GONZÁLEZ, A. (compiladores). Estudios sobre historia y ambiente en América. Vol. I. México: El Colegio de México - Instituto Panamericano de Geografía e Historia, 1999, p. 1-22.

NASH, C. Environmental History, Philosophy and Difference. Journal of Historical Geography, 2000, Vol. $26 \mathrm{~N}^{\circ}$ 1, p. 23-27.

NAYLOR, S. Discovering nature, rediscovering the self: natural historians and the landscapes of Argentina. Environment and Planning D: Society and Space, 2001, Vol. 19, p. 227-247.

NAYLOR, S. Historical geography: natures, landscapes, environments. Progress in Human Geography, 2006, Vol. 30, № 6, p. 792-802.
NOGUÉ FONT, J. y RUFÍ, J. Geopolítica, identidad y globalización. Barcelona: Editorial Ariel, 2001.

NORTON, W. La condición actual de la Geografía Histórica. En: CORTEZ, C. (compilador). Geografía histórica. México: Instituto Mora - Universidad Autónoma Metropolitana, 1991, p. 55-85.

OLWIG, K. Historical geography and the society/nature "problematic": the perspective of J. F. Schouw, G. P. Marsh and E. Reclus. Journal of Historical Geography, 1980, Vol. 6, $\mathrm{N}^{\circ} 1$, p. 29-45.

PÁDUA, J. Um sopro de destruição. Pensamento político e crítica ambiental no Brasil escravista (1786-1888). Rio de Janeiro: J. Zahar Editor, 2004.

PÁDUA, J. As bases teóricas da história ambiental. Estudos avançados, 2010, Vol. 24, $N^{\circ} 68$, p. 81-101.

PONTING, C. Historia verde del mundo. Barcelona: Editorial Paidós, 1992.

PRIETO, M. y ABRAHAM, E. Historia ambiental del sur de Mendoza (siglos XVI al $X I X)$. Los factores críticos de un proceso de desertificación. Bamberger Geograsphische Schriften, 1998, Vol. 15, p. 277-297.

RADKAU, J. Qué es la historia del medio ambiente. En: GONZÁLEZ DE MOLINA, M. y MARTÍNEZ, J. (editores). Historia y ecología. Madrid: Marcial Pons Editores, 1993, p. 119146.

REYES HERNÁNDEZ, H.; AGUILARROBLEDO, M.; AGUIRRE RIVERA, J. y TREJO VÁZQUEZ, I. Cambios en la cubierta vegetal y uso del suelo en el área del proyecto PujalCoy, San Luis Potosí, México, 1973-2000. Investigaciones Geográficas - Boletín del Instituto de Geografía UNAM, 2006, N59, p. 26-42.

RODRIGUEZ, J. A. Cunill Grau: el hombre de los mil paisajes. Geoenseñanza, 2001, Vol. 6, №2, p. 279-288.

SAID, E. Orientalismo. Madrid: Debate, 2002. 
SACK, R. D. Human Territoriality: its theory and history. Cambridge: Cambridge University Press, 1986.

SAUER, C. La explotación destructiva en la expansión colonial moderna. Memorias del Congreso Geográfico Internacional, 1938, Vol. II, Sec. IIIc, p. 494-499 (traducción de Guillermo Castro Herrera).

SAUER, C. The agency of man on the Earth. In: THOMAS, W. (compilador). Man's role in changing the face of the Earth. Chicago: Chicago University Press, 1956, p. 49-69.

SAUER, C. Introducción a la Geografía Histórica. En: CORTEZ, C. (compilador). Geografía histórica. México: Instituto Mora Universidad Autónoma Metropolitana, 1991, p. 35-52.

SAURÍ PUJOL, D. Tradición y renovación en la geografía humana ambientalista. Documents d'analisi geográfica, 1993, $\mathrm{N}^{\circ} 22$, p. 139-157.

SIMMONS, I. Interpreting nature. Cultural constructions of the environment. London: Routledge, 1996.

SMITH, C.T. Geografía histórica: tendencias actuales y perspectivas futuras. En: RANDLE, P. H. Teoría de la Geografía. Vol. 1. Buenos Aires: GAEA-OIKOS, 1984, p. 272-303.

STEWART, M. Environmental History: profile of a developing field. The History Teacher, 1998, Vol. 31, №3, p. 351-368.

SUNYER, MARTIN, P. La Geografía Histórica y las nuevas tendencias en la Geografía Humana. En: LINDÓN, A. y HIERNAUX, D. (directores). Los giros de la Geografía Humana. Iztapalapa: Anthropos - UAM, 2010, p. 143-173.

THOMAS, K. O homem e o mundo natural. Mudanças de atitude em relação às plantas e aos animais (1500-1800). São Paulo: Companhia das Letras, 1993.

THOMAS, W. (editor). Man's role in changing the face of the Earth. Chicago: The University of Chicago Press, 1956.
URTEAGA, L. La tierra esquilmada. Las ideas sobre la conservación de la naturaleza en la cultura española del siglo XVIII. Barcelona: Serbal-CSIC, 1987.

URTEAGA, L. Ideas medioambientales en el siglo XVIII: naturaleza, clima y civilización. Madrid: Akal, 1997.

WATTS, M. Hazards and Crisis: A Political Economy of Drought and Famine in Northern Nigeria. Antipode, 1983, Vol. 15, $\mathrm{N}^{\circ} 1, \mathrm{p}$. 24-34.

WILLIAMS, M. The relations of environmental history and historical geography. Journal of Historical Geography, 1994, Vol. 20, $\mathrm{N}^{\circ} 1$, p. 3-21.

WORSTER, D. The wealth of nature. Environmental history and the ecological imagination. Oxford: Oxford University Press, 1993.

WORSTER, D. Doing environmental history. In: WORSTER, D (editor). The ends of the Earth. Perspectives on modern environmental history. Cambridge: Cambridge University Press, 1994.

ZIMMERER, K. Cultural ecology (and political ecology) in the 'environmental borderlands': exploring the expanded connectivities within geography. Progress in Human Geography, 2007, Vol. 3, №2, p. 227-244.

ZUSMAN, P. Sociedades Geográficas na promoçao dos saberes a respeito do território. Estratégias políticas e acadêmicas das instituiçoes geográficas na Argentina (1879-1942) e no Brasil (1838-1945). São Paulo: Dissertacao de Mestrado, Programa de Pós-graduaçao em Integraçao da Amërica Latina, Universidad de São Paulo, 1996.

ZUSMAN, P. ¿Unidad o diversidad en la Geografía Histórica? En: DELGADO, O. y CRISTANCHO, H. (editores). Globalización y Territorio. Reflexiones Geográficas en América Latina. Bogotá: Universidad Nacional de Colombia, 2009, p. 67-82. 